\title{
Pengaruh Interval Waktu Panen \\ terhadap Produksi Biomassa Chlorella sp. dan Melosira sp. untuk Penangkapan Karbon secara Biologi
}

\section{The Effect of Harvesting Frequency on Biomass Production of Chlorella sp. and Melosira sp. for Biological Carbon Capture}

\author{
JOKO PRAYITNO'1, IKLIMA IKA RAHMASARI ${ }^{1,2}$, AGUS RIFAI $^{1}$ \\ ${ }^{1}$ Pusat Teknologi Lingkungan, BPPT, Gedung 820Teknologi Kebumian Kawasan Puspiptek Tangerang Selatan \\ ${ }^{2}$ Program Studi Biologi, Fakultas Sains dan Teknologi, Universitas Islam Negeri Syarif Hidayatullah Jakarta \\ Telp. : +6221 75791377/79/81 ext. 4126. Email: joko.prayitno@bppt.go.id
}

\begin{abstract}
The aim of this study was to determine the effect of harvesting frequency on the growth of Chlorella sp. and Melosira sp. and on their total biomass production to estimate the amount of carbon fixed during 11 days of culture. Chlorella sp. and Melosira sp. were cultured in f/2 medium in seawater. The biomass was harvested at harvesting intervals of every day (P1), every 2 days (P2) and every 3 days (P3). The biomass of Chlorella sp. harvested at $P 1, P 2$ and $P 3$ were $0,49 \mathrm{~g} / \mathrm{L}, 0,43 \mathrm{~g} / \mathrm{L}$, and $0,35 \mathrm{~g} / \mathrm{L}$, respectively. The highest total biomass production of Chlorella sp. after 11 days of cultivation was obtained from $P 1$ $(8,80 \mathrm{~g} / \mathrm{L})$, while total biomass production at $P 2$ and $P 3$ were $52 \%(4,59 \mathrm{~g} / \mathrm{L})$ and $30 \%(3,25 \mathrm{~g} / \mathrm{L})$ of that $P 1$, respectively. The biomass harvested at $P 1, P 2$ and $P 3$ were $2,41 \mathrm{~g} / \mathrm{L}, 1,40 \mathrm{~g} / \mathrm{L}$, and 1,63 g/L. Total biomass production of Melosira sp. during 11 days of cultivation for $P 1, P 2$ and $P 3$ were $34,56 \mathrm{~g} / \mathrm{L}, 17,33$ $\mathrm{g} / \mathrm{L}, 11,20 \mathrm{~g} / \mathrm{L}$, respectively. Our results showed that the highest total biomass production of both Chlorella sp. and Melosira sp. were obtained from harvesting every day. The estimated value of $\mathrm{CO}_{2}$ biofixation based on biomass production by Chlorella sp. and Melosira sp. were 1,5 g/L/day and 5,9 g/L/day, respectively.
\end{abstract}

Keywords: biomass, microalgae, Chlorella sp, harvesting interval, Melosira sp, carbon capture

\begin{abstract}
ABSTRAK
Penelitian ini bertujuan untuk mengetahui pengaruh interval waktu panen biomassa mikroalga terhadap pertumbuhan Chlorella sp. dan Melosira sp., dan perolehan total biomassanya untuk estimasi $\mathrm{CO}_{2}$ yang difiksasi selama kultur 11 hari. Chlorella sp. dan Melosira sp. dikultivasi dalam media air laut yang berisi nutrien $\mathrm{f} / 2$. Biomassa mikroalga dipanen dengan interval waktu panen tiap hari (P1), tiap 2 hari (P2) dan tiap 3 hari (P3). Sebagai kontrol (P0), biomassa mikroalga dipanen hanya pada akhir percobaan yaitu di hari ke-11. Kelimpahan sel kultur Chlorella sp. pada perlakuan P1, P2 and P3 masing-masing adalah $2,38 \times 10^{6} \mathrm{sel} / \mathrm{mL}, 2 \times 10^{6} \mathrm{sel} / \mathrm{mL}, 1,5 \times 10^{6} \mathrm{sel} / \mathrm{mL}$, sedangkan total biomassa yang diperoleh masing-masing adalah 0,49 $\mathrm{g} / \mathrm{L}, 0,43 \mathrm{~g} / \mathrm{L}$, dan $0,35 \mathrm{~g} / \mathrm{L}$. Total produksi biomassa Chlorella sp. tertinggi yang diperoleh selama 11 hari kultivasi dijumpai pada perlakuan P1 $(8,80 \mathrm{~g} / \mathrm{L})$, sedangkan total produksi biomassa pada P2 dan P3 hanya 52\% (4,59 g/L) dan 30\% (3,25 g/L) dari total biomassa P1. Kelimpahan sel Melosira sp. yang dipanen dengan interval P1, P2 dan P3 masing-masing adalah $4,28 \times 10^{6} \mathrm{sel} / \mathrm{mL}, 2,22 \times 10^{6} \mathrm{sel} / \mathrm{mL}$, dan $2,36 \times 10^{6} \mathrm{sel} / \mathrm{mL}$, dan biomassa yang diperoleh masing-masing adalah $2,41 \mathrm{~g} / \mathrm{L}, 1,40 \mathrm{~g} / \mathrm{L}$, dan 1,63 $\mathrm{g} / \mathrm{L}$. Total produksi biomassa Melosira sp. yang diperoleh selama 11 hari kultivasi untuk perlakuan P1, P2 dan P3 masing-masing adalah 34,56 g/L,17,33 g/L, dan 11,20 g/L. Hasil percobaan ini menunjukkan bahwa total produksi biomassa tertinggi pada Chlorella sp. dan Melosira sp.dijumpai pada kultur yang dipanen setiap hari. Estimasi serapan karbon berdasarkan biomasa yang dihasilkan oleh Chlorella sp dan Melosira sp. masing-masing adalah 1,5 g/L/hari dan 5,9 g/L/hari.
\end{abstract}

Kata kunci: biomassa, mikroalga, Chlorella sp., interval panen, Melosira sp., penangkapan karbon

\section{PENDAHULUAN}

Mikroalga merupakan mikroorganisme fotosintetik yang berpotensi digunakan sebagai agen biologis penangkap karbon dalam kegiatan mitigasi gas rumah kaca khususnya gas $\mathrm{CO}_{2}^{(1,2)}$. Aplikasi teknologi mikroalga untuk penangkapan karbon telah dilakukan di Indonesia sejak dekade lalu melalui penerapan teknik kultivasi mikroalga diantaranya dalam unit fotobioreaktor skala bangku(2,3). Dalam unit fotobioreaktor tersebut, gas $\mathrm{CO}_{2}$ dari udara 
ditangkap dan dirubah oleh mikroalga menjadi senyawa organik yang menjadi penyusun tubuhnya melalui proses fotosintesis. Jumlah $\mathrm{CO}_{2}$ yang dikonversi oleh mikroalga menjadi senyawa organik tercermin dari biomassa yang dihasilkan. Semakin banyak biomassa yang dihasilkan mengindikasikan bahwa semakin banyak pula gas $\mathrm{CO}_{2}$ yang dikonversi menjadi senyawa organik oleh mikroalga. Besaran konversi gas $\mathrm{CO}_{2}$ dari udara menjadi biomassa mikroalga tergantung dari jenis mikroalga yang digunakan ${ }^{(4,5)}$.

Jenis mikroalga yang banyak digunakan sebagai penghasil biomassa adalah Chlorella sp. Mikroalga Chlorella sp. telah lama dikultivasi dan dimanfaatkan untuk berbagai keperluan termasuk dalam penangkapan karbon. Selain lebih tahan terhadap kontaminan dan perubahan lingkungan, Chlorella sp. dapat menghasilkan biomassa yang tinggi hingga $5.3 \mathrm{~g} / \mathrm{L}^{(6)}$. Selain Chlorella yang merupakan jenis mikroalga hijau, mikroalga jenis diatom juga dikenal menghasilkan produksi biomassa yang tinggi(7).

Kultur mikroalga yang digunakan untuk penangkapan karbon dalam fotobioreaktor harus dipanen secara berkala agar laju pertumbuhan mikroalga dalam fotobioreaktor tetap tinggi sehingga efisiensi serapan karbon tetap maksimal. Kultivasi mikroalga untuk penangkapan karbon dalam fotobioreaktor masih mengalami beberapa kendala yang membatasi penerapan praktisnya dalam skala besar. Kendala tersebut antara lain adalah produksi biomassa yang rendah (maksimum 1 $\mathrm{g} / \mathrm{L})$ serta biaya panen dan pemulihan yang tinggi ${ }^{(8)}$, terutama untuk jenis mikroalga yang tidak mudah mengendap seperti Chlorella. Proses panen dan pemulihan biomassa ini dapat menghabiskan sekitar $20-30 \%$ dari total biaya produksi ${ }^{(9)}$. Proses panen berfungsi untuk memisahkan mikroalga dari medium kulturnya sehingga diperoleh biomassa mikroalga. Biomassa yang didapat kemudian diproses lebih lanjut untuk menghasilkan produk yang bermanfaat. Sedangkan proses pemulihan bertujuan untuk menumbuhkan kembali kultur mikroalga sehingga dihasilkan biomassa dalam jumlah yang diinginkan secara berkelanjutan. Salah satu alternatif untuk menurunkan biaya panen tersebut adalah dengan menggunakan jenis mikroalga yang mudah mengendap seperti jenis diatom sehingga lebih mudah ditangani pada waktu proses pemanenan. Jenis diatom yang memiliki potensi untuk digunakan diantaranya adalah Melosira sp.

Waktu panen dan pemulihan pertumbuhan biomassa menjadi faktor penting dalam sistem kultivasi mikroalga untuk penangkapan karbon dalam skala besar. Proses panen dan pemulihan yang terlalu sering belum tentu dapat menghasilkan biomassa yang besar begitu juga sebaliknya. Namun demikian, penelitian mengenai waktu panen dan pemulihan yang tepat untuk menghasilkan biomassa yang besar belum banyak dilakukan. Penelitian yang berkaitan dengan produksi biomassa mikroalga lebih banyak difokuskan pada nutrisi, pengaruh faktor fisik kimia, teknik kultur dan teknik pemanenan ${ }^{(10,11,12)}$. Karena itu, dalam penelitian ini dilakukan studi pengaruh frekuensi waktu panen untuk mengetahui interval waktu panen yang tepat sehingga diperoleh produksi biomassa yang besar dan stabil dalam periode yang lama. Jenis mikroalga yang digunakan adalah Chlorella $\mathrm{sp}$ dan Melosira sp. Data yang diperoleh dapat digunakan selanjutnya sebagai acuan dalam proses kultivasi mikroalga di fotobioreaktor skala besar untuk tujuan penangkapan karbon.

\section{BAHAN DAN METODE}

\subsection{Jenis Mikroalga}

Strain mikroalga yang digunakan dalam percobaan ini adalah Chlorella sp. dan Melosira sp. Chlorella sp. diperoleh dari koleksi kultur mikroalga P2O LIPI dan telah dikulturkan dalam fotobioreaktor di BPPT. Melosira sp. diperoleh dari kultur PT Pertamina yang berasal dari koleksi kultur P2O LIPI.

\subsection{Perbanyakan Mikroalga}

Media yang digunakan untuk kultivasi mikroalga adalah air laut yang berisi media f/2. Media $\mathrm{f} / 2$ terdiri dari hara makro $\mathrm{NaNO}_{3} 75$ $\mathrm{mg} / \mathrm{L}, \quad \mathrm{NaH}_{2} \mathrm{PO}_{4} \cdot \mathrm{H}_{2} \mathrm{O} 5 \mathrm{mg} / \mathrm{L}$, hara mikro $\mathrm{Na}_{2}$ EDTA $4,16 \mathrm{mg} / \mathrm{L}, \mathrm{FeCl}_{3} \cdot 6 \mathrm{H}_{2} \mathrm{O} 3,15 \mathrm{mg} / \mathrm{L}$, $\mathrm{CuSO}_{4} .5 \mathrm{H}_{2} \mathrm{O} \quad 0,01 \mathrm{mg} / \mathrm{L}, \mathrm{ZnSO}_{4} .7 \mathrm{H}_{2} \mathrm{O} \quad 0,022$ $\mathrm{mg} / \mathrm{L}, \mathrm{CoCl}_{2} \cdot 6 \mathrm{H}_{2} \mathrm{O} 0,01 \mathrm{mg} / \mathrm{L}, \mathrm{MnCl}_{2} \cdot 4 \mathrm{H}_{2} \mathrm{O} 0,18$ $\mathrm{mg} / \mathrm{L}, \mathrm{NaMoO}_{4} .2 \mathrm{H}_{2} \mathrm{O} 0.006 \mathrm{mg} / \mathrm{L}$, biotin dan vitamin $B 12 \quad 0,5 \mu \mathrm{g} / \mathrm{L}$, dan thiamin $0,1 \mathrm{mg} / \mathrm{L}$ Khusus untuk kultur Melosira sp. ditambahkan pula $\mathrm{Na}_{2} \mathrm{SiO}_{3} .9 \mathrm{H}_{2} \mathrm{O} 30 \mathrm{mg} / \mathrm{L}$.

Chlorella sp. dan Melosira sp. mula-mula dikultur dalam $1 \mathrm{~L}$ air laut berisi $\mathrm{f} / 2$ dalam botol kaca yang diberi aerasi dan pencahayaan selama 24 jam. Setelah berumur 7 hari, kultur diperbanyak dengan cara memindahkan $50 \%$ kultur ke $500 \mathrm{~mL}$ media baru dan penambahan $500 \mathrm{~mL}$ media ke dalam kultur lama dan sehingga diperoleh volume kultur $2 \mathrm{~L}$. Setelah 7 hari, kultur diperbanyak kembali hingga mencapai volume $5 \mathrm{~L}$ dengan populasi 1,2 $\mathrm{x}$ $10^{5} \mathrm{sel} / \mathrm{mL}$.

\subsection{Pelaksanaan Percobaan}

Percobaan kultivasi mikroalga untuk melihat pengaruh frekuensi panen terhadap 
produksi biomassa dilakukan dalam botol plastik dengan volume kerja 2 L. Mikroalga dikulturkan terlebih dahulu selama 5 hari, setelah itu kultur mulai dipanen sebanyak $10 \%$. Frekuensi panen yang dicoba adalah: panen setiap hari ( $\mathrm{P} 1)$, tiap dua hari (P2) dan tiap tiga hari (P3). Kultur yang tidak dipanen hingga akhir percobaan diperlakukan sebagai kontrol (P0). Kultur yang dipanen kemudian ditambahkan media baru sebanyak volume yang dipanen (top up) dan diberi nutrien $\mathrm{f} / 2$ dengan jumlah sesuai dengan jumlah media yang ditambahkan. Kultur diinkubasi dalam ruangan dengan pencahayaan dari lampu tabung selama 24 jam dan suhu ruangan diatur pada $25^{\circ} \mathrm{C}$. Kultur diaerasi selama 24 jam dengan menggunakan pompa udara. Percobaan berlangsung selama 11 hari. Masing-masing perlakuan memiliki ulangan 3 kali.

Sampling dilakukan setiap hari mulai dari hari ke-1 hingga akhir percobaan yaitu pada hari ke-11. Sebelum pengambilan sampel, kultur diaduk merata agar homogen dan tidak ada sel yang mengendap. Parameter yang diukur adalah kelimpahan sel dan biomassa. Biomassa mikroalga diukur berdasarkan berat kering setelah sampel disaring dan dioven pada suhu $80^{\circ} \mathrm{C}$ selama 24 jam. Kelimpahan sel dihitung menggunakan Haemocytometer dari sampel mikrolga yang telah diberi larutan Lugol $2 \mathrm{~mL}$. pH meter diukur setiap hari untuk mengetahui kondisi kultur.

Analisis statistik terhadap data yang diperoleh dilakukan untuk melihat pengaruh perbedaan interval panen menggunakan uji one way ANOVA. Hasil yang menunjukan pengaruh signifikan, diuji lanjut dengan Duncan Multiple Range Test pada tingkat kepercayaan $5 \%$.

\subsection{Estimasi Serapan Karbon}

Untuk menghitung serapan karbon (gas $\mathrm{CO}_{2}$ ) oleh mikroalga Chlorella sp. dan Melosira sp. digunakan faktor konversi yang digunakan oleh Chisti $(2007)^{(13)}$, yaitu 1,88 atau $1 \mathrm{~kg}$ biomassa yang dihasilkan setara dengan 1,88 kg karbon yang difiksasi.

\section{HASIL DAN PEMBAHASAN}

\subsection{Pengaruh Interval Waktu Panen Terhadap Pertumbuhan Chlorella sp.}

Nilai kelimpahan sel Chlorella sp. di awal kultivasi adalah $0,21 \times 10^{6} \quad \mathrm{sel} / \mathrm{mL}$. Nilai kelimpahan sel Chlorella sp. pada hari ke-5 pada perlakuan kontrol, P1, P2 dan P3 masingmasing adalah $0,89,0,90,0,76$ dan $0,79 \times 10^{6}$ $\mathrm{sel} / \mathrm{mL}$ (Gambar 1). Nilai kelimpahan sel tertinggi pada perlakuan kontrol terjadi pada hari ke-9 dengan jumlah sel sebesar $0,96 \times 10^{6}$ sel/mL. Nilai kelimpahan sel tertinggi pada perlakuan $\mathrm{P} 2$ terjadi pada hari ke-10 dengan jumlah sel sebesar $2 \times 10^{6} \mathrm{sel} / \mathrm{mL}$. Nilai kelimpahan sel tertinggi pada perlakuan P1 dan P3 terjadi di akhir kultivasi dengan jumlah sel masing-masing sebesar $2,38 \times 10^{6} \mathrm{sel} / \mathrm{mL}$ dan $1,56 \times 10^{6} \mathrm{sel} / \mathrm{mL}$.

Berdasarkan hasil yang diperoleh terlihat bahwa fase adaptasi (fase lag) Chlorella sp. di semua perlakuan berlangsung sangat cepat yakni kurang dari 24 jam, sehingga tidak terlihat dalam grafik. Fase lag yang singkat pada kultur mikroalga terjadi karena mikroalga yang dijadikan inokulum berada pada fase eksponensial dalam media kultur yang sama.

Fase eksponensial Chlorella sp. pada perlakuan kontrol terjadi pada hari ke-1 hingga hari ke-5. Fase eksponensial yang singkat pada perlakuan kontrol terjadi karena pemberian nutrisi hanya dilakukan di awal kultivasi saja, sehingga pada hari ke-6 pertumbuhan Chlorella sp. pada perlakuan kontrol mulai melambat. Hal ini terjadi karena adanya kompetisi nutrisi yang jumlahnya mulai tidak mencukupi untuk pertambahan populasi. Berdasarkan hasil penelitian ini dapat diketahui bahwa kelimpahan sel Chlorella sp. mencapai puncaknya hingga hari ke-6.

Fase eksponensial pada perlakuan P1 terjadi pada hari ke-1 hingga hari ke-11. Kelimpahan sel yang meningkat hingga akhir kultivasi pada perlakuan P1 disebabkan karena adanya proses panen dan pemulihan dan penambahan nutrisi yang dilakukan setiap hari, sehingga masih memicu pembelahan sel Chlorella sp. hingga hari ke-11.
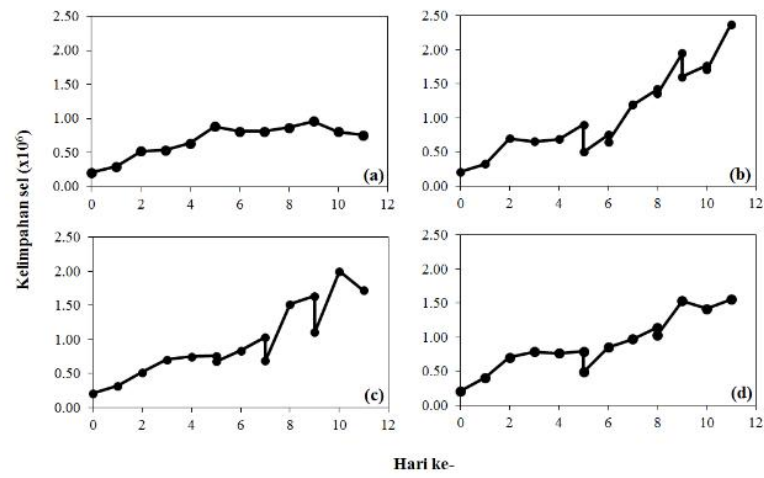

Gambar 1. Kelimpahan sel Chlorella sp. dengan interval waktu panen berbeda, (a) panen di akhir percobaan (Kontrol); (b) panen setiap hari (P1); (c) panen setiap 2 hari $(\mathrm{P} 2)$; (d) panen setiap 3 hari (P3).

Fase eksponensial di perlakuan P2 terjadi pada hari ke-1 hingga hari ke-10. Perlakuan P2 mulai mengalami penurunan kelimpahan sel 
pada hari ke-11. Fase eksponensial di perlakuan P3 terjadi pada hari ke-1 hingga hari ke-9 dan mulai mengalami penurunan kelimpahan sel pada hari ke-10. Hal ini menunjukkan bahwa pada perlakuan panen dan pemulihan setiap 2 dan 3 hari tidak terlalu efektif untuk mempertahankan fase pembelahan sel pada kultur Chlorella sp.

Biomassa Chlorella sp. menunjukkan pola pertumbuhan yang terus meningkat hingga akhir kultivasi (Gambar 2). Biomassa awal Chlorella sp. yang tercatat adalah $0,12 \mathrm{~g} / \mathrm{L}$. Biomassa Chlorella sp. pada hari ke-5 pada perlakuan kontrol, P1, P2 dan P3 masingmasing adalah sebesar 0,21, 0,187, 0,21 dan $0,24 \mathrm{~g} / \mathrm{L}$. Biomassa tertinggi pada semua perlakuan terjadi di hari ke-11 dengan nilai biomassa pada perlakuan kontrol, P1, P2 dan P3 masing-masing adalah sebesar 0,33 g/L; 0,49 g/L; 0,43 g/L; dan 0,35g/L.

Biomassa Chlorella sp. pada perlakuan kontrol dan P3 selama percobaan berlangsung memiliki pola yang hampir sama. Nutrisi pada perlakuan kontrol hanya diberikan pada awal kultivasi saja, sedangkan pada perlakuan P3 pemberian nutrisi dilakukan kembali pada hari ke-5 dan ke-9 sesuai dengan jadwal panen. Hasil percobaan menunjukkan bahwa biomassa pada perlakuan P1 dan P2 meningkat secara signifikan pada hari ke-11. Hal ini membuktikan bahwa panen setiap hari dan setiap 2 hari dapat meningkatkan pertumbuhan biomassa pada Chlorella sp. Walaupun demikian, perlakuan P1 memiliki biomassa tertinggi dibandingkan perlakuan P2.
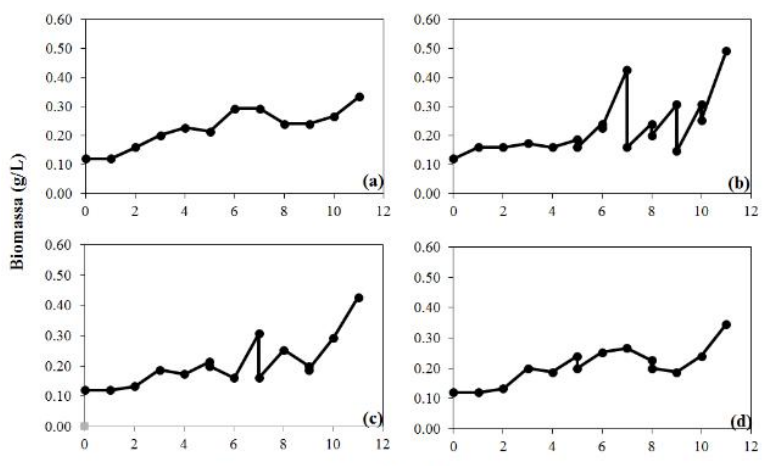

Hari ke-

Gambar 2. Biomassa Chlorella sp. dengan interval waktu panen berbeda, (a) panen di akhir percobaan (Kontrol); (b) panen setiap hari (P1); (c) panen setiap 2 hari (P2); (d) panen setiap 3 hari (P3).

\subsection{Pengaruh Interval Waktu Panen Terhadap Pertumbuhan Melosira sp.}

Nilai kelimpahan sel Melosira sp. di awal kultivasi adalah $0,03 \times 10^{6} \mathrm{sel} / \mathrm{mL}$. Kelimpahan sel Melosira sp. mengalami kenaikan yang pesat pada hari ke-5. Nilai kelimpahan sel Melosira sp. pada hari ke-5 pada perlakuan kontrol, P1, P2 dan P3 masing-masing adalah $0,72 \times 10^{6} \mathrm{sel} / \mathrm{mL} ; 1,59 \times 10^{6} \mathrm{sel} / \mathrm{mL} ; 0,19 \times 10^{6}$ $\mathrm{sel} / \mathrm{mL}$; dan $0,77 \times 10^{6} \mathrm{sel} / \mathrm{mL}$. Kelimpahan sel tertinggi pada perlakuan kontrol dicapai pada hari ke-9 dengan jumlah sel sebanyak $1,27 \times 10^{6}$ $\mathrm{sel} / \mathrm{mL}$ (Gambar 3). Nilai kelimpahan sel tertinggi Melosira sp. pada perlakuan P1, P2 dan P3 dicapai pada hari ke-10 dengan jumlah sel masing-masing adalah $4,28 \times 10^{6}, 2,22 \times 10^{6}$, dan $2,36 \times 10^{6} \mathrm{sel} / \mathrm{mL}$.

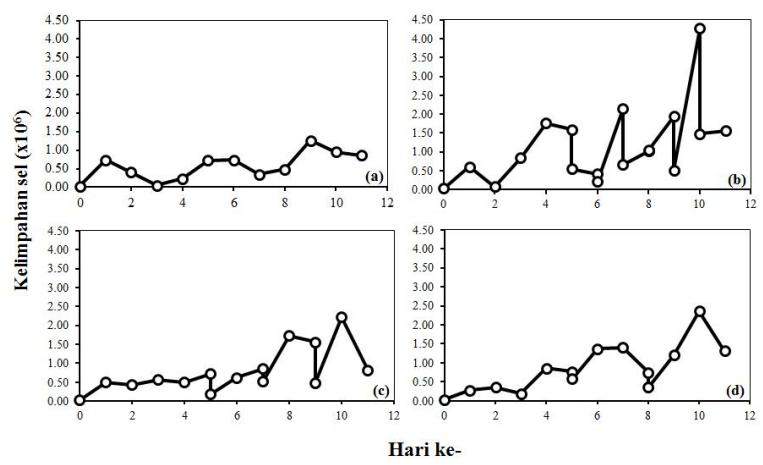

Gambar 3. Kelimpahan sel Melosira sp. dengan interval waktu panen berbeda, (a) panen di akhir percobaan (Kontrol); (b) panen setiap hari (P1); (c) panen setiap 2 hari (P2); (d) panen setiap 3 hari (P3).

Fase lag Melosira sp. berlangsung kurang dari 24 jam disebabkan karena media kultur yang digunakan sama seperti media sebelumnya. Oleh karena itu, sama seperti pada Chlorella sp., fase lag Melosira sp. pada semua perlakuan tidak terlihat pada kurva pertumbuhan. Selama kultivasi, kultur Melosira sp. beberapa kali terlihat mengendap di dasar wadah kultur. Kelas Bacillarioceae merupakan diatom bentik yang hidup di dasar badan air dan sering melekat pada bagian subtrat bawah air ${ }^{14}$. Sifat mudah mengendap pada Melosira sp. ini dapat menguntungkan proses pemanenan.

Kelimpahan sel pada perlakuan P1, P2 dan P3 menunjukkan peningkatan yang signifikan pada hari ke-10. Hal ini disebabkan karena penambahan nutrisi secara berkala pada ketiga perlakuan ini, sehingga dapat memicu pembelahan sel Melosira sp. Perlakuan P1 memiliki pola kelimpahan sel yang tertinggi dibandingkan perlakuan lainnya. Perlakuan P2 dan P3 memiliki pola kelimpahan sel yang hampir sama. Hal ini menunjukkan bahwa Melosira sp. dapat menghasilkan kelimpahan sel yang tinggi jika diberikan nutrisi setiap hari. 
Biomassa awal Melosira sp. adalah sebesar $0,48 \mathrm{~g} / \mathrm{L}$. Nilai biomassa tertinggi pada perlakuan kontrol, P1, P2 dan P3 terjadi pada hari ke-11 dengan berat masing-masing adalah $1,45,2,41,1,40$ dan 1,63 g/L. Pertumbuhan biomassa Melosira sp. menunjukkan pola yang terus meningkat hingga akhir kultivasi (Gambar 4).

Berbeda dengan kelimpahan sel yang mengalami penurunan pada akhir kultivasi, biomassa Melosira sp. pada perlakuan kontrol terlihat meningkat hingga akhir kultivasi. Hasil pengamatan dibawah mikroskop menunjukkan bahwa sel-sel Melosira sp. muda yang baru tumbuh dan ukurannya lebih kecil terkadang mendominasi pada kultur, sehingga nilai biomassa dalam penelitian ini tidak berbanding lurus dengan nilai kelimpahan sel.

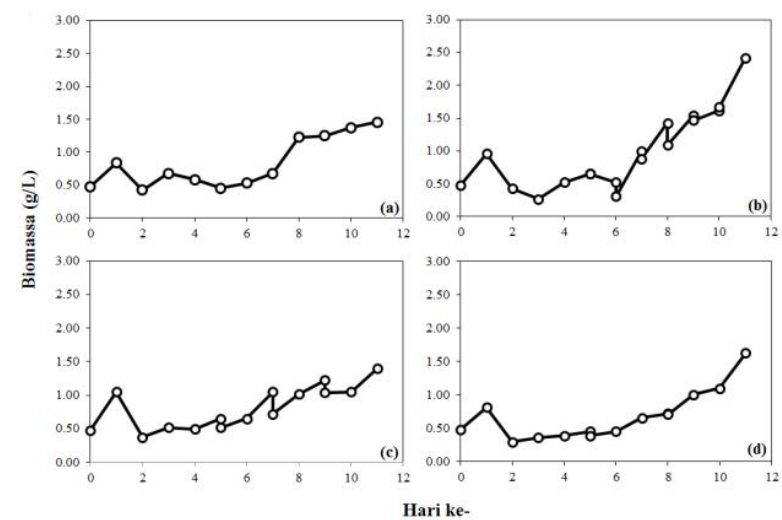

Gambar 4. Biomassa Melosira sp. dengan interval waktu panen berbeda, (a) panen di akhir percobaan (Kontrol); (b) panen setiap hari (P1); (c) panen setiap 2 hari (P2); (d) panen setiap 3 hari $(P 3)$.

Perlakuan P1 menghasilkan nilai biomassa tertinggi dibandingkan dengan perlakuan kontrol, P2, dan P3. Pola pertumbuhan Melosira sp. pada perlakuan kontrol, P2, dan P3 terlihat hampir sama. Hal ini menunjukkan bahwa panen yang dilakukan setiap hari pada kultur Melosira sp. dapat memicu pembentukan biomassa yang lebih baik dibandingkan panen setiap 2 dan 3 hari.

Chlorella sp. dan Melosira sp. pada penelitian ini dikultivasi selama 11 hari dengan 4 perlakuan interval waktu panen. Perlakuan interval waktu panen ini dilakukan setelah kultur berumur 5 hari. Sebagian besar kultur dipanen dan sebagian kultur lainnya $(10 \% \mathrm{v} / \mathrm{v})$ digunakan untuk pertumbuhan selanjutnya. Hal ini mengacu pada hasil penelitian Ferreira et al. ${ }^{(15)}$ yang mendapatkan kelimpahan sel tertinggi pada kultur yang dipanen sebanyak $10 \%$ dari volume total kultur. Pemanenan dan penambahan nutrisi medium secara berkala setelah panen menyebabkan pertumbuhan sel mikroalga terpacu dan dapat meningkatkan biomassa. Pertambahan kelimpahan sel mikroalga berperan penting dalam akumulasi biomassa. Berdasarkan hasil penelitian ini, kelimpahan sel dan biomassa tertinggi ditemukan pada kultur Chlorella sp. dan Melosira sp. yang dipanen setiap hari. Semakin sering dilakukannya panen dan recovery kultur, proses pembelahan sel akan semakin cepat dan meningkatkan kepadatan sel. Hal ini berkaitan dengan adanya pasokan nutrisi yang melimpah serta berkurangnya hasil metabolisme yang bersifat toksik di dalam kultur. Metabolit yang dihasilkan mikroalga yang disebut growth inhibitor (GI) telah dilaporkan dapat menghambat pertumbuhan organisme lain maupun pertumbuhan mikroalga itu sendiri(16). Penambahan medium kultur yang baru ke dalam kultur dapat mengurangi $\mathrm{Gl}$ sehingga kepadatan sel akan meningkat ${ }^{(17)}$.

\subsection{Total Produksi Biomassa Chlorella sp. dan Melosira sp.}

Pemanfaatan mikroalga yang berkaitan dengan produksi biomassa sangat bergantung pada hasil panen yang diperoleh. Biomassa yang diperoleh akan diproses lebih lanjut untuk menghasilkan produk yang lebih bermanfaat. Selain informasi mengenai biomassa yang diperoleh tiap panen, juga diperlukan informasi mengenai jumlah biomassa pada periode waktu tertentu. Untuk itu, parameter lain yang penting diketahui dalam produksi biomassa mikroalga adalah total produksi biomassa dalam suatu periode tertentu (Tabel 1). Dalam penelitian ini, total produksi biomassa didapatkan dari total penjumlahan biomassa yang diperoleh pada semua proses pemanenan selama 11 hari.

Hasil uji ANOVA menunjukkan bahwa interval waktu panen berpengaruh nyata terhadap total produksi biomassa Chlorella sp. dan Melosira sp. $(P<0,05)$. Total produksi biomassa tertinggi pada kedua jenis mikroalga ini terdapat pada perlakuan P1. Perlakuan P1 adalah kultur yang dipanen setiap hari mulai dari hari ke- 5 hingga hari ke- 11 .

Hasil uji Duncan terhadap Chlorella sp. menunjukkan bahwa total produksi biomassa perlakuan P1 $(8.80 \mathrm{~g})$ lebih tinggi dibandingkan dengan perlakuan kontrol $(1,33 \mathrm{~g}), \mathrm{P} 2(4,59 \mathrm{~g})$ dan P3 (3,25 g) (Tabel 1). Total biomassa perlakuan P2 dan P3 juga lebih tinggi dibandingkan dengan kontrol, namun perlakuan P2 tidak berbeda nyata dengan perlakuan P3. Hasil uji Duncan menunjukkan bahwa total produksi biomassa Melosira sp. paling tinggi 
dijumpai pada perlakuan P1 (34,51 g) dibandingkan dengan kontrol $(5,81 \mathrm{~g})$, $\mathrm{P} 2$ $(17,33 \mathrm{~g})$ dan P3 $(11,20 \mathrm{~g})$.

Tabel 1. Total produksi biomassa Chlorella sp. dan Melosira sp. selama 11 hari pada masing-masing perlakuan.

\begin{tabular}{ccc}
\hline & \multicolumn{2}{c}{$\begin{array}{c}\text { Total Produksi Biomassa } \\
\text { (g/L/11 hari) }\end{array}$} \\
\cline { 2 - 3 } Perlakuan & Chlorella sp. & $\begin{array}{c}\text { Melosira } \\
\text { sp. }\end{array}$ \\
\hline Kontrol & $1,33^{\mathrm{a}}$ & $5,81^{\mathrm{a}}$ \\
$\mathrm{P} 1$ & $8,80^{\mathrm{c}}$ & $34,51^{\mathrm{c}}$ \\
P2 & $4,59^{\mathrm{b}}$ & $17,33^{\mathrm{b}}$ \\
P3 & $3,25^{\mathrm{b}}$ & $11,20^{\mathrm{ab}}$ \\
\hline SE & $\pm 0,86$ & $\pm 3,39$ \\
\hline Keterangan: Huruf superskrip yang berbeda pada \\
kolom yang sama menunjukkan perbedaan yang nyata \\
berdasarkan uji Duncan ( $\mathrm{a}=0,05)$. SE: Standard Error \\
of Mean
\end{tabular}

Total produksi biomassa dalam penelitian ini sejalan dengan hasil penelitian yang dilakukan oleh Cai et al. ${ }^{(18)}$. Cai melakukan kultivasi terhadap Nannochloropsis salina dalam botol gelas ukuran $2 \mathrm{~L}$ selama 18 hari. Total produksi biomassa $N$. salina yang dipanen setiap hari mencapai 2,58 $\mathrm{g} / \mathrm{L}$ dengan volume yang dipanen sebanyak $50 \%$. Hasil penelitian yang serupa juga telah dilaporkan oleh Chiu et al. ${ }^{(19)}$. Total produksi biomassa Nannochloropsis oculata NTCU-3 yang dipanen setiap hari dengan volume yang dipanen $50 \%$ mencapai $5,96 \mathrm{~g} / \mathrm{L}$ selama 8 hari.

\subsection{Nilai pH Kultur}

Pertumbuhan mikroalga, selain dipengaruhi oleh nutrisi juga dipengaruhi oleh faktor lingkungan. Salah satu faktor lingkungan yang sangat penting bagi pertumbuhan mikroalga adalah $\mathrm{pH}$ kultur. $\mathrm{pH}$ kultur merupakan faktor penting yang dapat mempengaruhi proses biologis pertumbuhan, metabolisme dan penyerapan ion oleh mikroalga Hasil pengukuran $\mathrm{pH}$ kultur Chlorella sp. dan Melosira sp.selama 11 hari dapat dilihat pada Gambar 5.

Nilai $\mathrm{pH}$ air laut yang digunakan untuk kultivasi mikroalga dalam percobaan ini adalah 7,8. Hasil pengukuran nilai $\mathrm{pH}$ kultur Chlorella sp. dan Melosira sp. berfluktuasi dengan kisaran nilai antara 8,33-9,18. Hanet al. ${ }^{(23)}$ menyatakan bahwa kisaran $\mathrm{pH}$ optimum untuk pertumbuhan mikroalga adalah 7-9. Oleh karena itu, nilai $\mathrm{pH}$ kultur pada penelitian ini masih dalam batas toleran pertumbuhan Chlorella sp. dan Melosira sp.

Nilai $\mathrm{pH}$ kultur pada Chlorella sp. dan Melosira sp. di semua perlakuan menunjukkan pola yang sama pada awal kultivasi. Selanjutnya, kisaran nilai $\mathrm{pH}$ pada setiap perlakuan mengalami perbedaan pola. Kultur yang di panen setiap hari memiliki kisaran nilai $\mathrm{pH}$ tertinggi, sedangkan kultur pada perlakuan kontrol memiliki nilai kisaran $\mathrm{pH}$ terendah hingga akhir kultivasi. Peningkatan nilai $\mathrm{pH}$ pada kultur dengan perlakuan panen disebabkan karena adanya penambahan nutrisi baru setelah proses panen. Hal ini diduga karena media $\mathrm{f} / 2$ mengandung nitrogen dalam bentuk nitrat. Penambahan nitrogen dalam bentuk nitrat dapat meningkatkan $\mathrm{pH}$ karena proses absorpsi nitrat menyebabkan satu ion $\mathrm{OH}^{-}$dilepaskan oleh mikroalga(20,21).

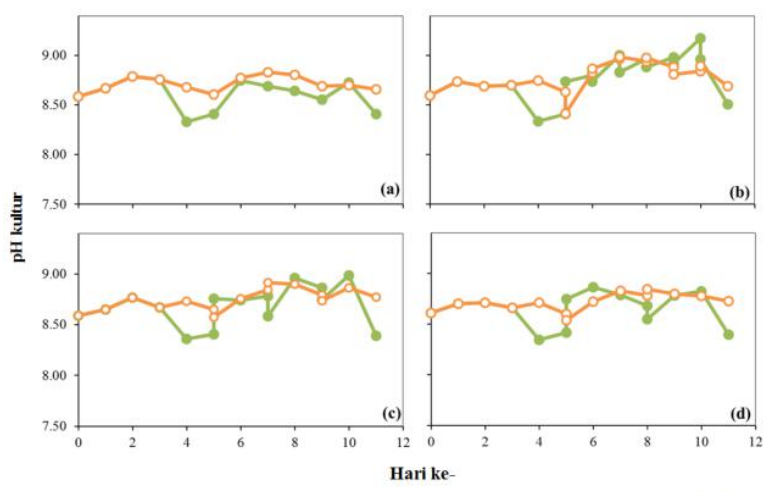

Gambar 5. Nilai pH kultur Chlorella sp. ( - ) dan Melosira sp. ( - ) dengan interval waktu panen yang berbeda, (a) panen di akhir percobaan (Kontrol); (b) panen setiap hari (P1); (c) panen setiap 2 hari (P2); (d) panen setiap 3 hari (P3).

\subsection{Estimasi Serapan Karbon oleh Chlorella sp. dan Melosira sp.}

Mikroalga menyerap gas $\mathrm{CO}_{2}$ dari udara yang selanjutnya digunakan sebagai bahan baku biosintesis senyawa-senyawa organik melalui proses fotosintesis. Laju serapan gas $\mathrm{CO}_{2}$ oleh mikroalga ditentukan oleh jenis mikroalga dan kondisi lingkungan. Mikroalga Chlorella sp., dan diatom telah banyak digunakan dalam penelitian untuk penangkapan karbon karena tingkat pertumbuhannya yang cepat dan lebih tahan terhadap perubahan kondisi lingkungan. Estimasi serapan karbon oleh Chlorella sp. dan Melosira sp. dalam percobaan ini dilakukan dengan menggunakan pendekatan faktor konversi 1,88, yaitu satu kg biomassa dihasilkan dari hasil penyerapan $1,88 \mathrm{~kg} \mathrm{CO}$. Berdasarkan faktor konversi tersebut, maka serapan karbon oleh Chlorella sp. dan Melosira sp. paling banyak terjadi pada kultur yang dipanen setiap hari, yaitu masing-masing 
sebesar 1,5 g/L/hari dan 5,9 g/L/hari (Tabel 2). Hasil estimasi serapan karbon oleh Chlorella sp. tersebut berada dalam rentang nilai serapan $\mathrm{CO}_{2}$ oleh mikroalga sejenis seperti yang telah dilaporkan sebelumnya, yaitu antara $0.87-3,45$ g/L/hari 22,23$)$

Tabel 1. Estimasi total serapan $\mathrm{CO}_{2}$ oleh Chlorella sp. dan Melosira sp..

\begin{tabular}{ccc}
\hline \multirow{2}{*}{ Perlakuan } & \multicolumn{2}{c}{$\begin{array}{c}\text { Total Serapan } \mathrm{CO}_{2} \\
\text { (g/L/hari) }\end{array}$} \\
\cline { 2 - 3 } & Chlorella sp. & $\begin{array}{c}\text { Melosira } \\
\text { sp. }\end{array}$ \\
\hline Kontrol & 0,22 & 0,99 \\
P1 & 1,50 & 5,90 \\
P2 & 0,78 & 2,96 \\
P3 & 0,56 & 1,91 \\
\hline
\end{tabular}

\section{KESIMPULAN} bahwa:

Dari percobaan ini dapat disimpulkan

a. Interval waktu panen berpengaruh nyata terhadap total produksi biomassa Chlorella sp.dan Melosira sp. Interval waktu panen yang menghasilkan biomassa tertinggi adalah panen setiap hari.

b. Kultur Chlorella sp. yang dipanen setiap hari menghasilkan total biomassa $8,8 \mathrm{~g} / \mathrm{L}$ dan Melosira sp. 34,51 g/L.

c. Estimasi serapan karbon oleh Chlorella sp dan Melosira sp. masing-masing adalah 1,5 $\mathrm{g} / \mathrm{L} / \mathrm{hari}$ dan $5,9 \mathrm{~g} / \mathrm{L} / \mathrm{hari}$.

\section{PERSANTUNAN}

Penulis mengucapkan terimakasih kepada Ibu Yana Meliana PT Pertamina atas pemberian kultur Melosira sp

\section{DAFTAR PUSTAKA}

1. Maity, J. P., Bundschuh, J., Chen, C. Y., \& Bhattacharya, P. (2014). Microalgae for third generation biofuel production, mitigation of greenhouse gas emissions and wastewater treatment: Present and future perspectives-A mini review. Energy, 78, 104-113.

2. Setiawan, A., Darmawan, R. A., \& Santoso, A. D. (2009). Penerapan teknologi fotobioreaktor mikroalga jenis air-lift untuk menyerap emisi gas $\mathrm{CO}_{2}$. J. Teknologi Lingkungan. Edisi Khusus, 49, 56.

3. Santoso, A. D., Darmawan, R. A., \& Susanto, J. P. (2016). Pengaruh laju alir injeksi gas emisi pada fotobioreaktor terhadap penyerapan $\mathrm{CO}_{2}$ oleh Chlorella sp. Jurnal Teknologi Lingkungan, 12(1), 1-6.
4. Lardon, L., Helias, A., Sialve, B., Steyer, J. P., \& Bernard, O. (2009). Life-cycle assessment of biodiesel production from microalgae. Environ. Sci Technol. 2009, 43:6475-6481.

5. Jacob-Lopes, E., Scoparo, C. H. G., Queiroz, M. I., \& Franco, T. T. (2010). Biotransformations of carbon dioxide in photobioreactors. Energy Conversion and Management, 51(5), 894-900.

6. Sun, N., WangY., Li Y.T., HuangJ.C. \& Chen, F. (2008). sugar-based growth, astaxanthin accumulation and carotenogenic transcription of heterotrophic Chlorella zofingiensis (Chlorophyta). Process Biochem. 43: 1288-1292.

7. Chen, P., Min M., Yifeng C., Liang W., Yecong Li, Qin Chen, Chenguang W., Yiqin W., Xiaoquan W., Yanling C., Shaobo D., Kevin H., Xiangyang L., Yuhuan L., Yingkuan W., Blanca M. \& Roger R. (2009). Review of the biological and engineering aspects of algae to fuels approach. Int $\mathrm{J}$ Agric \& Biol Eng.2(4): 1-29.

8. Mulyanto, A. (2010). Mikroalga (Chlorella sp.) sebagai agensia penambat gas karbon dioksida. J. Hidrosfir Indonesia. 5(2): 13-23.

9. Grima, E.M., Belarbi, E.H., Acién Fernández, F.G., Robles Medina, A.\& Chisti, Y. (2003). Recovery of microalgal biomass and metabolites: process options and economics. Biotechnol. Adv.20: 491-515.

10. Pires, J. C. M., Alvim-Ferraz, M. C. M., Martins, F. G., \& Simões, M. (2012). Carbon dioxide capture from flue gases using microalgae: engineering aspects and biorefinery concept. Renewable and Sustainable Energy Reviews, 16(5), 30433053.

11. Morales, P., Martinez L.A.\& Camalich J.M.Carpizo. (2015). Dry Weight, carbon, $\mathrm{C} / \mathrm{N}$ Ratio, hydrogen, and chlorophyll variation during exponential growth of selected microalgae species used in aquaculture. CICIMAR Oceanides. 30(1): 33-43.

12. Farrelly, D. J., Everard, C. D., Fagan, C. C., \& McDonnell, K. P. (2013). Carbon sequestration and the role of biological carbon mitigation: a review. Renewable and Sustainable Energy Reviews, 21, 712-727.

13. Chisti, Y. (2007). Biodiesel from microalgae. Biotechnology advances, 25(3), 294-306.

14. Ferreira, M., Paula C., Pedro S., Jaime F. \& Ana O. (2009). Enriching rotifers with 
"Premium" microalgae Nanochloropsis gaditana. Mar Biotechnol. 11: 585-595.

15. Armanda, D.T. (2013). Pertumbuhan kultur mikroalga diatom Skeletonema costatum (Greville) Cleve Isolat Jepara pada Medium f/2 dan Medium Conway. Bioma.2(1):49-63.

16. Richmond, A., Zhang C.W. \& Yair Z. (2003). Efficient use of strong light for high photosynthetic productivity: interrelationships between the optical path, the optimal population density and cellgrowth inhibition. Biomolecular Engineering.20: 229-236.

17. Prihantini, N.B., Winni R. \& Wisnu W. (2007). Pengaruh Variasi Fotoperioditas terhadap pertumbuhan Chlorella dalam Medium Basal Bold. Biota.12(1): 32-39.

18. Cai, T., Stephen Y.P., Ratanachat R. \& Yebo L. (2013). Cultivation of Nannochloropsis salina using anaerobic digestion effluent as a nutrient source for biofuel production. Applied Energy. 108: 486-492.

19. Chiu, S., Chien Y.K., Ming T.T., Seow C.O., Chiun H.C. \& Shih S.L. (2009). Lipid acumulation and $\mathrm{CO} 2$ utilization of
Nannochloropsis oculata in response to $\mathrm{CO}_{2}$ aeration. Bioresource Technology. 100: 833-838.

20. Han, F., Jianke H., Yuanguang Li, Eiliang W., Minxi W., Guomin S. \& Jun W. (2013). Enhanced lipid productivity of Chlorella pyrenoidosa through the culture strategy of semi-continuous cultivation with nitrogen limitation and $\mathrm{pH}$ control by $\mathrm{CO}_{2}$. Bioresource Technology. 136: 428-424.

21. Scherholz, M. L., \& Curtis, W. R. (2013). Achieving $\mathrm{pH}$ control in microalgal cultures through fed-batch addition of stoichiometrically-balanced growth media. BMC biotechnology, 13(1), 39.

22. Chiu, S. Y., Kao, C. Y., Chen, C. H., Kuan, T. C., Ong, S. C., \& Lin, C. S. (2008). Reduction of $\mathrm{CO}_{2}$ by a high-density culture of Chlorella sp. in a semicontinuous photobioreactor. Bioresource technology, 99(9), 3389-3396.

23. Fan, L. H., Zhang, Y. T., Zhang, L., \& Chen, H. L. 2008. Evaluation of a membranesparged helical tubular photobioreactor for carbon dioxide biofixation by Chlorella vulgaris. Journal of Membrane Science, 325(1), 336-345 